could thus be accounted for. We conclude, therefore, that the comet of 1772 was not that of Biela.

2. The first comet of I I 8 is regarded by Dr. Weiss as a probable nember of the Biela group." This body, discovered by Pons, was visible only four days. Its elements, as computed by Pogson, have a striking resemblance to those of Biela's comet, the longitudes of the ascending nodes differing by only $I^{\circ}$. There can be little doubt that it was connected, in its origin, with the comet of Biela.

3. The companion of Biela, observed in 1846 and 1852 , is another comet of the same cluster. The fact that several cometary masses move in orbits almost identical, may afford a plausible explanation of the division of Biela's comet. Was one member of the group overtaken by another as they were approaching perihelion in 1845 , and was their separation after imperfect collision the phenomenon observed at that epoch?

4. The comet detected by Pogson, at Madras, on December 2 and 3,1872 , may have been another member of the same family. Its perihelion passage occurred nearly three months after the time computed for that of Biela. Prof. Newton has remarked t that so great a lengthening of the pericd could not probably be explained by planetary perturbation.

M. Hoek has shown $\neq$ that certain comets have been associated in groups before entering the solar domain. When the members of such cometary systems are widely separated, they may pass round the sun in very different orbits. The comets, however, which constitute the Biela cluster must have entered our system at small distances from each other, since their orbits are nearly coincident. These orbits, between longitude $255^{\circ}$ and $265^{\circ}$, pass within no great distance of that of Jupiter. The group had perhaps made its first perihelion passage in a parabolic orbit. Receding from the sun, it fell under the controlling influence of Jupiter; the comets had various positions in relation to the planet, and hence the orbits resulting from the attraction of the latter were slightly different.

We might regard the comet of 1772 , the companion of Biela, and Pogson's comet of 1872 , as probably identical, but for the small increase of distance between the two Biela-comets in the interval from 1846 to 1852 . The period would be about 2456 days.

That the comets of this cluster have been moving in their present orbits but a comparatively short time is rendered probable by the fact that no two of the members hitherto detected have become widely separated, and that, notwithstanding the frequency of the return to perihelion, the meteoric debris is much less diffused than in the case of other known streams.

Were all the members of this cluster originally united in a single comet, or did they cnter the solar systcm as a group? To this question, perhaps, no satisfactory answer can yet be given. It seems probable, however, that the united masses would have formed a somewhat conspicuous object, too brilliant to have entirely escaped observation.

Bloomington, Indiana, April 15

\section{Earthquake in Dumfries}

Winle sitting in my lonely house in a retired but beautiful glen of Dumfriesshire, I was aroused on the evening of Wednes. day I6th current, at ten minutes to ten o'clock, by one of the most singular noises ever I had listened to. The tone of it was somewhat like thunder, but it did not rise and fall in pitch. It las'ed, perhaps, for twenty seconds, and was accompanied by a slight tremor. At first I thought it was a two-horsed carriage coming, and at a lumbering pace, and then, with some hesita. tion, I took it for thunder, but next day I found that it was generally recognised as an earthquake. The shaking was very perceptible in some localities. It extended through the parishes of Closeburn, Morton, Penpont, Glencairn, and Tynron, over a Iength, I am safe to say, of ten miles. Dr. Grierson of Thornhill Museum felt it as a rude shock. In Tynron village there was some alarm, as one family thought it was the wall of the churchyard that had fallen. On December 24, last year, a similar shock was felt in some parts of Upper Nithsdale. Although I have resided for many years in Dumfriesshire, these are the only occasions on which there was any surmise of an earthquake. The local papers have said almost nothing about it, but I am sure this will interest some of your readers.

Tynron School, April 23

J. SHaw

* Astr. Nach., No r7ra

+ American Journal of Science, April 1873.

\pm Ilonthly Notices of the R.A.S., vol, xxv. r. 243 .
East India Museum

Altow me to make yet another suggestion (in addition to those of P.L.S. and Prof. Newton), with regard to the disposal of the natural history collections at the India House. It seems to me to be one of the greatest popular delusions, that specimens of natural history necessarily require lofty halls and spacious galleries for their preservation and exhibition in a useful manner. I hold, on the contrary, that, with few exceptions, they far better serve educational and scientific purposes when arranged in ordinary apartments. All the scientific work in the British Museum is done in small rooms; and the palatial galleries with their crowded myriads of specimens and miles of glass cases, however instructive they may be (or might be made) to the public, are a positive hindrance to scientific work. I am very much mistaken if all the India House natural history collections might not be suitably placed in two or three ordinary sitting rooms, and so arranged in cabinets and boxes as to be far more convenient for reference and study than they have ever been. The rent of a moderate-sized house in an airy situation, say $250 l$. with an equal sum for the salary of an efficient Curator, and a small grant for cabinets and the necessary books of reference, is all the expense required to make this interesting collection completely accessible to all who wish to consult it. Every one interested in Indian natural history would then visit it. It would again receive gifts of collections from travellers, Indian Officers, and other persons interested in the natural history of the East; and its increase in value from this source alone might go far towards furnishing a tangible equivalent for the expense incurred, while it would certainly render the collection, a better representation of the Indian fauna than it is at present, and more worthy of a place, at some future time, in the proposed grand Indian Museum.

Such a modest establishment would also, 1 believe, do much good by showing at how small an expense a really useful scientific museum may be kept up, and would thus encourage the formation of local museums in cases where $20,000 \%$. or $30,000 \%$. cannot be raised for a building. It would not, of course, be a show museum for the uneducated public to wander and gaze in; -the British Museum serves that purpose. But it would prove greatly superior to any such mere exhibition, as a means of furnishing definite information on Indian zoology, and enabling any intelligent inquirer to obtain some idea of the many wonderful and beautiful forms of life which characterise, what is at once the smallest and the richest in proportion to its extent, of the great zoological regions of the globe.

Alfred R. Wallace

Ir will be graatly to be regretted if even your suggestions are adopted as a remedy for the present neglect, and the claims of scientific men and of the public at large for a Government museum be abandoned. It is very desirable for Indian interests that the Museum shall be, as before, connected with the Indian department.

It is quite true accommodation in the sky-parlours, with casual access by a lift, is given for the industrial collections so well conducted by Dr. Forbes Watson, and which collections, as chairman of the Indian Committee of the Society of Arts, I feel bound to contend for as of great value to England and to India.

There is no solid ground for letting the Government go. They acquired in the like way the property of the Levant Company, and attempted to shirk the rights and obligations, but were compelled to maintain the public buildings, churches, hospitals and burial-grounds at Constantinople, Smyrna, \&c. It must be owned they constantly attempt to evade the obliga. tions.

They are now engaged in paying off the stock of the old East Indis Company, of which they have acquired the territory, houses, property, prerogatives, \&c., and they must simulta. neously accept every obligation, pecuniary and moral.

This was a museum for the service of England and the service of India, and there is no reason why it should not be kept up. There is, it is true, a growing licence in this day for representing us as usurpers and oppressors of India, whereas the pexce, pros. perity, and progress of India have been created by us, and were we to withdraw, would be destroyed by the sanguinary conflicts of the various races of conquered and conquerors constituting the populations.

We ought to stand on our right to share in the prosperity of India as a prerogative belonging to us. Besides, for the benefit of India, the collections are kept up by Englishmen, for there $i_{j}$ 